\title{
Eco-eficiência na Produção de Cera de Carnaúba no Município de Campo Maior, Piauí, 2004
}

\author{
Francisco Prancacio Araújo de Carvalho ${ }^{1}$ \\ Jaíra Maria Alcobaça Gomes ${ }^{2}$
}

Resumo: A Copernicia prunifera (Miller) H.E. Moore ou carnaúba gera um material sobre as folhas usado na fabricação de cera, matéria-prima de inúmeros produtos industriais. O Brasil é o único produtor de cera de carnaúba e o estado do Piauí, um importante influente. Neste, as condições naturais do município de Campo Maior favorecem a incidência da carnaubeira e sua tradição histórica na produção de cera tornaram-no um pólo regional. O objetivo geral é analisar, na produção de cera de carnaúba, os elementos e indicadores de eco-eficiência - associação de eficiência econômica com baixo impacto ambiental -, os específicos são: avaliar qualitativamente o consumo de materiais e de energia, emissão de substâncias tóxicas, existência de reciclagem de materiais e uso de recursos renováveis; construir e analisar indicadores de ecoeficiência. As informações e dados originaram-se de pesquisa direta em indústria de cera que representasse o padrão técnico e a participação no mercado no estado. Os resultados mostram que a produção industrial de cera impacta o meio ambiente com uso intenso de água, utilização da lenha e diesel como fonte energética, consumo de produtos químicos

\footnotetext{
${ }^{1}$ Mestre em Desenvolvimento e Meio Ambiente/ PRODEMA/TROPEN/UFPI Instituição: Prof. Assistente do Dep. de Economia da Universidade Federal do Piauí (UFPI). E-mail: prancacio@ig.com.br

${ }^{2}$ Doutora em Economia Aplicada / ESALQ / USP Instituição: Profa. Associada do Dep. de Economia e do PRODEMA/TROPEN da Universidade Federal do Piauí (UFPI). E-mail: jairamag@uol.com.br
} 
e emissão de poluentes, entretanto, atende importantes elementos de eco-eficiência como a reutilização de materiais e consumo de materiais renováveis.

Palavras-chaves: Cera de carnaúba. Eco-eficiência. Nordeste brasileiro. Piauí.

Classificação JEL: O18, Q01, Q2, M14

Abstract: The Copernicia prunifera (Miller) H.E. Moore or "carnauba” generates a material from the leaves used in the wax production, raw material of countless industrial products. Brazil is the only producer of carnauba wax and the state of Piauí, an important influential. In this, the natural conditions of the district of Campo Maior favor the incidence of the carnauba and its historical tradition in the wax production, turned it a regional pole. The general goal is to analyze, in the carnauba wax production, the elements and the eco-efficiency indicators - economical efficiency associated with low environmental impact. The specific goals are: to evaluate, qualitatively, the materials and energy consumption, toxic substances emissions, existence of recycling of materials and use of renewable resources; to build and to analyze eco-efficiency indicators. The information and data originated from direct research in a wax industry that represented the technical pattern and the participation in the market in the State. The results show that the industrial production of wax affect the environment with intensive use of water, use of wood and diesel as energy source, chemical products consumption and pollutants emissions, however, it attends important eco-efficiency elements as the recycling of materials and consumption of renewable materials.

Key-words: Carnauba wax. Eco-efficiency. Brazil Northeast. State of Piauí.

JEL classification: O18, Q01, Q2, M14 


\section{Introdução}

A carnaúba foi considerada a "árvore da vida" por apresentar numerosas e importantes finalidades pelo naturalista Humboldt quando, no século XVIII, conheceu-a em terra brasileira. É uma palmeira nativa do Brasil, embora cresça com facilidade em qualquer clima tropical e existam palmeiras da carnaúba na África Equatorial, no Ceilão, no Equador, na Tailândia e na Colômbia, é apenas no ambiente seco das caatingas do Nordeste, especialmente nos estados do Piauí, Ceará e Rio Grande do Norte, que ela se encontra em condições de exploração econômica. É um tipo de planta adaptada ao clima seco e se desenvolve de forma espaçada em solos arenosos e alagadiços, várzeas e margens dos rios de regiões de clima quente.

A mais relevante atividade associada à exploração econômica da carnaúba no estado do Piauí inicia-se pela extração de um material ceroso ou cutícula que reveste as folhas. Esse material é resultado de uma condição genética da planta, um mecanismo natural de defesa contra agentes externos, principalmente a incidência de elevadas temperaturas, que evita a perda excessiva de água e mantém o equilíbrio de água no interior da planta. Essa cutícula depois de extraída é chamada de pó de carnaúba e torna-se matéria-prima básica para produção da cera, que tem grande importância para indústria química, eletrônica, cosmética, alimentícia e farmacêutica. O Brasil é o único país do mundo que produz e exporta cera de carnaúba.

Considerando a importância da produção de cera de carnaúba na composição da dinâmica econômica, histórica e social do Piauí e, especificamente, de Campo Maior, torna-se relevante verificar o grau de impacto ambiental dessa atividade, o que fundamenta a realização do presente trabalho, o qual tem origem no problema de pesquisa formulado a partir da seguinte questão: o processo de produção de cera de carnaúba é eco-eficiente?

A metodologia consistiu na construção e análise de indicadores de eco-eficiência em indústria de cera que representasse o padrão técnico e grau de impacto ambiental no âmbito do Piauí.

O objetivo geral é analisar os elementos e indicadores de eco-eficiência, associação de eficiência econômica com baixo impacto ambiental, 
na produção de cera de carnaúba, em Campo Maior (PI). Especificamente, avaliar o consumo de materiais e consumo de energia nessa atividade produtiva, identificar as emissões de substâncias tóxicas, a existência de reciclagem de materiais e o uso de recursos renováveis.

O artigo compõe-se de três seções principais: a primeira aborda as mudanças no ambiente dos negócios com o advento da questão ambiental, a segunda a delimitação da área de estudo e os procedimentos para cálculo dos indicadores e, a terceira analisa os elementos e indicadores de eco-eficiência na produção de cera de carnaúba.

\section{Eco-eficiência: empresa e meio ambiente}

As mudanças de compreensão e comportamento sobre o meio ambiente elevaram as demandas pela eficiência econômica de processos e produtos, criando premissas convergentes entre o meio ambiente e o desenvolvimento de atividades empresariais. Entretanto, a adoção da gestão ambiental pelas empresas não se processou de forma generalizada e imediata, pois era limitada diante da concepção de que lucro e meio ambiente eram adversários naturais.

Para Vinha (2003), acreditava-se que as medidas de gestão ambiental, além de reduzir lucros, obrigariam repasse de custos aos consumidores, elevando preços. Essa concepção resultava do alto custo da tecnologia ambiental, em virtude de não estar essa tecnologia nem tão disponível nem tão aperfeiçoada quanto hoje. Em alguns anos, os custos da tecnologia ambiental se alteraram e a concepção de altos custos foi transformada.

[...] em poucos anos, ficou patente que as tecnologias ambientais tinham um potencial inverso, isto é, reduziam custos por meio de uma melhor racionalização dos processos produtivos, particularmente no uso de insumos e no desperdício, levando à rápida disseminação da gestão ambiental baseada no gerenciamento da qualidade total (VINHA, 2003, p.176).

As condições favoráveis aos negócios, resultantes do barateamento dos custos das tecnologias ambientais criaram um cenário promissor para as empresas, ampliando a rentabilidade com racionalização de processos 
e respeito ao meio ambiente. Esse é o modelo de gestão eco-eficiente.

Stephan Schmidheiny, empresário suíço fundador do World Business Council for Sustainable Development (WBCSD), afirma que o termo eco-eficiência surge da necessidade de apresentar uma proposta empresarial de atuação na área ambiental para a Conferência do Rio, em 1992. Buscava-se um conceito que sintetizasse a finalidade de negócios engajados numa perspectiva de desenvolvimento sustentável e, em 1991, o WBCSD definiu eco-eficiência como o melhor termo para exprimir eficiência econômica e ecológica. Essa noção vem sendo disseminada em empresas, universidades e organizações, estabelecendo-se como um instrumento de mensuração e avaliação de desempenho empresarial e que desperta maior atenção por parte dos governos e sociedades.

A eco-eficiência é alcançada mediante o fornecimento de bens e serviços a preços competitivos que satisfaçam as necessidades humanas e tragam qualidade de vida, ao mesmo tempo em que reduz progressivamente o impacto ambiental e o consumo de recursos ao longo do ciclo de vida, a um nível no mínimo, equivalente à capacidade de sustentação estimada da Terra. (CEBDS, 2004).

A eco-eficiência visa, portanto, a produção sustentável de bens e serviços para a sociedade, agregada de valor, não pela ampliação do consumo de recursos naturais, mas sim, pela sua redução e, minimização ou eliminação da geração de qualquer tipo de poluição.

Ao aliar desempenho econômico com melhorias ambientais, o conceito não se contrapõe a concepção de limite do crescimento econômico e ao processo de acumulação de capital. Por essa razão, é bem aceito por grande parte dos empresários. Configura-se, na verdade, como promotor do desenvolvimento sustentável, ampliando, de maneira prática e objetiva, os fundamentos da sustentabilidade, construídos pelos manifestos sociais e individuais do movimento ambientalista.

Certamente seguir parâmetros sustentáveis requer grandes esforços no âmbito social, econômico e ambiental. A eco-eficiência apresenta-se como um significativo avanço na área ambiental, principalmente por atuar junto ao empresariado que, historicamente, despertou pouca responsabilidade para com a natureza. Ao estabelecer-se como uma contribuição empresarial para uma sociedade sustentável, a eco-eficiência pode ajudar 
as empresas no crescimento mais qualitativamente que quantitativamente, provendo mais serviço, benefício e valor, em lugar de transformar mais materiais em energia e desperdício. A adoção de princípios ecoeficientes melhora, ainda, a qualidade de vida das pessoas ao reduzir a poluição ambiental e gerar produtos de qualidade superior.

Os sete elementos da eco-eficiência, segundo Almeida (2002), são:

1. redução do consumo de materiais com bens e serviços;

2. redução do consumo de energia com bens e serviços;

3. redução da emissão de substâncias tóxicas;

4. intensificação da reciclagem de materiais;

5. maximização do uso sustentável de recursos renováveis;

6. prolongamento da durabilidade dos produtos;

7. agregação de valor aos bens e serviços.

Estes elementos podem ser vistos como correlacionados com três objetivos (WBCSD, 2004): o primeiro diz respeito à redução do consumo de recursos que inclui a minimização da utilização de energia, materiais, água e solo, englobando a reciclabilidade e a durabilidade do produto e fechando o ciclo dos materiais; o segundo, redução do impacto na natureza, que inclui a minimização de emissões gasosas, descargas líquidas, eliminação de desperdícios e dispersão de substâncias tóxicas, assim como o fomento da utilização sustentável dos recursos renováveis; e o terceiro, aumentar o valor do produto ou serviço que significa beneficiar os clientes através da funcionalidade, flexibilidade e modularidade dos produtos, criando serviços adicionais (tais como: manutenção, serviços de melhoria e troca), concentrando-se na venda das necessidades funcionais que os clientes, de fato, querem. Vender um serviço, em vez do produto em si, favorece a possibilidade do cliente receber a mesma necessidade funcional com menos materiais e recursos. Do mesmo modo, melhora as perspectivas de fechar o ciclo dos materiais, porque a responsabilidade e a propriedade e, por conseguinte, a preocupação pela utilização eficiente fica do lado do fornecedor de serviços.

Concretizar esses elementos, em processos dinâmicos nas empresas incorre em dificuldades que inspiram determinação e empenho do empresariado. Este deve manter uma cultura progressiva de desenvolvimento eco-eficiente, empenhando-se na educação ambiental e treinamento dos seus funcionários, assim como no investimento em 
sistemas de gestão e avaliação ambiental de modo a promover resultados eficientes em processos e produtos.

Calcula-se a eco-eficiência a partir da fórmula básica que quantifica a relação entre valor do produto ou serviço e a influência ambiental.

\section{Valor do produto ou serviço}

Eco-eficiência =

Influência ambiental

O valor do produto ou serviço pode ser expresso pela quantidade do produto vendido ou vendas líquidas. A influência ambiental, inclui aspectos relacionados a criação de bens e serviços e ao seu consumo ou utilização, como, por exemplo, o uso de matérias-primas e insumos, assim como, resíduos, sejam líquidos, sólidos ou gasosos causados pela produção e consumo de um bem ou serviço.

Na Cúpula Mundial sobre Desenvolvimento Sustentável em 2002, Rio +10 , ocorrida em Johannesburg, o setor empresarial definiu sua ação de conduta não apenas no campo da eco-eficiência, incorporou também a Responsabilidade Social Corporativa, tornando esses os dois pilares básicos do desenvolvimento sustentável no mundo empresarial.

\section{Procedimentos metodológicos}

O universo da pesquisa é o estado do Piauí, onde se desenvolve grande parte da extração do pó cerífero e produção de cera de carnaúba da região do Nordeste e do Brasil. O Piauí apresenta 11 microrregiões produtoras de pó cerífero, das 15 existentes no estado. A maior concentração da produção de pó cerífero, historicamente, encontra-se na microrregião de Campo Maior. Os fatores que determinaram a escolha do município de Campo Maior para realização desse estudo foram:

1. Dispõem de condições naturais propícias para o desenvolvimento da carnaúba, pois seus altos índices de pluviometria média durante o ano, condições do solo, clima e relevo, contribuem para gerar áreas alagadiças no período chuvoso, ambientes favoráveis para disseminação natural da carnaubeira. A forte insolação em um período seco bem definido favorece a produção do pó cerífero de carnaúba; 
2. A sociedade campomaiorense empenha-se, tradicionalmente, na atividade de exploração da carnaúba, gerando oportunidades de trabalho e renda nos seus diversos segmentos de aproveitamento, principalmente artesanato, produção de pó cerífero e produção de cera de carnaúba;

3. Na microrregião de Campo Maior todos os municípios produzem pó cerífero, sendo o município de Campo Maior um dos principais responsáveis por essa dinâmica produtiva, representando, historicamente, o maior produtor regional;

4. Encontram-se indústrias de cera artesanais e modernas responsáveis por uma significativa parcela da produção e exportação de cera do estado do Piauí e região Nordeste.

A fonte dos dados foi proveniente de pesquisa direta em indústria de cera com tecnologia de produção moderna que representasse o padrão técnico do segmento no Piauí e participação significativa no mercado internacional de cera. Quanto ao padrão técnico, todos as indústrias do estado e Região Nordeste têm grau similar de tecnologia e organização do trabalho, entretanto, a empresa selecionada é a maior em termos de volume de produção e exportação no Piauí. Em 2004, exportou 1.900 toneladas de cera, 35,61 \% de todo a cera vendida ao exterior pelo Estado que foi de $5.336 .025 \mathrm{~kg}, 37,35 \%$ da cera exportada pelo Brasil, segundo dados do Ministério do Desenvolvimento e Comércio Exterior (MDIC, 2005). O certo grau de homogeneização técnica no setor permite qualificar a indústria selecionada como representativa do grau de impacto sobre a natureza do processo produtivo de cera.

Aplicou-se questionário composto por duas dimensões, uma econômica e outra ambiental, em 22 de dezembro de 2004, ao gerente de produção da indústria de cera. A partir das informações e, dos dados referentes à produção no ano de 2004, fez-se uma análise do processo, seguida de uma avaliação qualitativa e quantitativa, em que se identificaram as implicações causadas na produção de cera pela utilização de energia, insumos e resíduos gerados e, construção e análise de indicadores que refletissem o grau de impacto sobre o meio ambiente. Esses indicadores foram divididos em indicadores de valor, oriundos da dimensão econômica e, indicadores de influência ambiental, oriundos da dimensão ambiental. Ao final, consolidaram-se esses indicadores, em indicadores sínteses que medem a razão entre as dimensões de valor e ambiental. 
A produção de cera foi de 1.900 toneladas em 2004, os dados da dimensão econômica permitiram a construção dos seguintes indicadores de valor:

a) Quantidade de cera produzida - mensurou-se pelo produto total, informado pela indústria, em kg, para 2004;

b) Lucro líquido na produção de cera - estimado, em Reais (R\$), pela diferença entre a receita total das vendas, menos o custo total de produção e venda.

A dimensão ambiental na produção de cera permitiu a construção dos seguintes indicadores de influência ambiental:

c) Consumo de energia - soma total de energia consumida na produção de cera em 2004, representada pelo consumo de energia elétrica usada na movimentação de motores e no escritório da indústria, energia oriunda da queima da lenha utilizada na geração de vapor para o processo industrial e, energia derivada da queima do diesel utilizado no transporte dos insumos para o processamento industrial e da cera levada ao porto em Fortaleza (CE). O consumo de energia elétrica, em $\mathrm{kWh}$ foi informado, pelo gerente de produção, com base no consumo médio mensal registrado nos talões emitidos pela fornecedora, Companhia Energética do Piauí (CEPISA). A queima da lenha foi transformada em energia com a referência Vale et. al. (2003) que considera a massa específica básica média da lenha de $0,61 \mathrm{~g} / \mathrm{cm}^{3}$ e seu poder calorífero líquido médio de $2.898,00 \mathrm{kcal} / \mathrm{kg}$. O total de lenha consumida na produção de cera, em $\mathrm{cm}^{3}$, multiplicado por 0,61 gerou o peso total de lenha em gramas que foi transformado em $\mathrm{kg}$ e multiplicado pelo valor calorífero da lenha, gerando o consumo total de energia derivada da lenha. Utilizou-se essa referência porque ela está próxima do poder calorífico médio da lenha brasileira e representa uma realidade local. A energia derivada do consumo de óleo diesel combustível foi calculada, considerando a referência do potencial energético do diesel, de 45,01 GJ/t, UNCTAD (2004), multiplicado pelo diesel consumido na produção e transporte da cera. Ao final, fez-se a conversão das medidas e somaram-se todas as energias, obtendo-se o consumo total de energia. $\mathrm{O}$ indicador consolidado mostra a razão entre a quantidade de cera (a) e o consumo de energia (c) e, entre o lucro líquido (b) e o consumo de energia (c).

d) Emissões de gases que contribuem para o efeito estufa - emissões 
totais de $\mathrm{CO}_{2}$, em kg, levando em conta as emissões provocadas pela queima do diesel usado no transporte, emissões referentes à queima da lenha e, aquela associadas ao consumo de energia elétrica. As emissões provocadas pelo diesel foram calculadas referenciando-se UNCTAD (2004), que destacou o fator de conversão para o diesel na ordem de 74,07 toneladas de $\mathrm{CO}_{2}$ por TJ de energia usada. Quanto às emissões provocadas pela queima da lenha, utilizou-se a referência do Ministério da Ciência e Tecnologia (MCT, 2005) que considera como fator de emissões da lenha, 29,9 t C/TJ. Como este fator não expressou a equivalência em $\mathrm{CO}_{2}$, utilizou-se o fator de conversão de "peat briquettes", uma espécie de massa de carvão de turfa (material fóssil, combustível, formado por matérias vegetais dentro da água em terrenos paludosos), citado em UNCTAD (2004), que teve o nível de emissão de 25,8 t C/TJ, próximo da lenha, representando 94,6 t CO 2 /TJ. As emissões de $\mathrm{CO}_{2}$ referentes ao consumo de eletricidade estão referenciadas em UNCTAD (2004) como 0,000057 t $\mathrm{CO}_{2} / \mathrm{kWh}$. A soma dos consumos de cada energia para 2004, multiplicados pelos seus respectivos fatores de conversões referentes às emissões, mantendo-se a mesma unidade, gerou o total de emissões na produção da cera. O indicador consolidado, mostra a contribuição para o efeito estufa por $\mathrm{kg}$ de cera (a)/(d) e o lucro líquido gerado por kg de $\mathrm{CO}_{2}$ emitido (b)/(d).

e) Consumo de materiais - total de insumos, em kg, necessários para fabricação de cera em 2004, que incluem: quantidade de pó cerífero, solvente, argilas, peróxido de hidrogênio, palha de arroz e tecido usado para filtragem. O pó cerífero é a matéria-prima básica da produção cera, medido em kg. As argilas são preparadas quimicamente para auxiliar a filtragem de substâncias, elas retêm as impurezas contidas na cera líquida e deixam-nas no filtro. Seu consumo foi medido, em kg, para 2004, pela proporção de argila usada para cada kg de cera produzida. O peróxido de hidrogênio $\left(\mathrm{H}_{2} \mathrm{O}_{2}\right)$ é a substância utilizada para clarificar a cera, é conhecida popularmente como água oxigenada e seu peso foi calculado da mesma forma que se calculou o consumo de argilas. O solvente é usado na fusão do pó em cera e seu consumo foi estimado, em kg, pelo número de vezes em que se abasteceu o reservatório. A palha de arroz facilita a drenagem do pó na primeira fase do processo, foi calculada, em kg pela proporção utilizada para cada kg de pó utilizado. Como se pôde observar, os pesos desses materiais 
foram fornecidos pela pesquisa direta em $\mathrm{kg}$, exceto o solvente que foi transformado em $\mathrm{kg}$ com referência da densidade de $0,7225 \mathrm{~g} / \mathrm{cm}^{3}$ $\left(20^{\circ} \mathrm{C}-4^{\circ} \mathrm{C}\right)$, fornecida pela divisão técnica da indústria. $\mathrm{O}$ indicador consolidado mostra o consumo de materiais por cera produzida $(\mathrm{a}) /(\mathrm{e})$ e, o consumo de materiais por lucro gerado (b)/(e).

f) Resíduos sólidos - foram medidos pela soma dos pesos, em kg, da borra (essencialmente formada por palha-de-arroz) que se torna resíduo na primeira etapa do processo; do barro, resíduos emitidos no filtro, uma mistura de argilas com impurezas; e tecido filtro, usado na filtragem da cera. A palha-de-arroz utilizada é seca e tem baixo índice de umidade. O peso total dos resíduos foi contabilizado pela soma das medidas da palha-de-arroz, argilas e impurezas e tecidos. Com a queima da lenha há a geração de cinzas, entretanto, não foi possível avaliar o peso total de cinzas geradas, portanto, as cinzas foram desconsideradas na composição dos resíduos. O indicador consolidado mede o consumo de resíduo por cera produzida (a)/(f) e geração de resíduo por lucro gerado (b)/(f).

g) Consumo de embalagem - é soma dos pesos das embalagens, em kg, usadas para acondicionar os 1.900 toneladas de cera produzidos em 2004. De acordo com a divisão técnica da empresa, em um saco comporta $25 \mathrm{~kg}$ de cera e cada embalagem pesa, em média, $150 \mathrm{~g}$. Calculou-se o total de sacos usados na produção para o ano de 2004 e multiplicou-se pelo peso unitário da embalagem, obtendo o consumo total de embalagens. As embalagens usadas no acondicionamento do pó comprado pela indústria, não foram adicionadas no consumo de embalagem, pois elas retornam para o produtor de pó. O indicador consolidado mede a relação entre o produto gerado e o peso das embalagens (a)/(g) e, o lucro e as embalagens (b)/(g).

h) Consumo de água - determinado pelo uso direto de água no processo. A indústria dispõe de um poço tubular, há uma caixa de 5 mil litros que é reabastecida continuamente para suprir a demanda de água. O consumo de água foi estimado, em kg, pelo número de vezes que a caixa foi reabastecida durante o ano de 2004. O indicador consolidado mede a exigência de água por kg de cera (a)/(h) e o consumo de água por lucro gerado (b)/(h). O Quadro 1 mostra sinteticamente os indicadores de eco-eficiência. 
Quadro 1 - Indicadores de eco-eficiência na produção de cera de carnaúba.

\begin{tabular}{|c|c|c|}
\hline \multirow{3}{*}{ DIMENSÃO } & \multicolumn{2}{|c|}{ INDICADORES DE ECO-EFICIÊNCIA } \\
\hline & \multirow{2}{*}{ INDICADORES GERAIS } & $\begin{array}{l}\text { INDICADORES CONSOLIDADOS* } \\
\text { Valor da cera (a) ou (b) }\end{array}$ \\
\hline & & $\begin{array}{l}\text { Influência ambiental (c) ou (d) ou } \\
\text { (e) ou (f) ou (g) ou (h) }\end{array}$ \\
\hline $\begin{array}{l}\text { ECONÔMICA } \\
\text { (Valor da cera) }\end{array}$ & $\begin{array}{l}\text { a. A quantidade de cera } \\
\text { produzida e vendida. } \\
\text { b. Lucro líquido na produção de } \\
\text { cera }\end{array}$ & $\begin{array}{l}\text { a / c. Exigência de energia por kg } \\
\text { de cera. } \\
\text { b / c. Exigência de energia por lucro } \\
\text { líquido. }\end{array}$ \\
\hline \multirow{6}{*}{$\begin{array}{l}\text { AMBIENTAL } \\
\text { (Influência } \\
\text { ambiental) }\end{array}$} & $\begin{array}{l}\text { c. Consumo de energia: diesel, } \\
\text { lenha, eletricidade. }\end{array}$ & \multirow{6}{*}{$\begin{array}{l}\text { a / d. Contribuição para o efeito } \\
\text { estufa por kg de cera. } \\
\text { b / d. Contribuição para o efeito } \\
\text { estufa por lucro líquido. } \\
\text { a / e. Exigência de materiais por kg } \\
\text { de cera. } \\
\text { b / e. Exigência de materiais por } \\
\text { lucro líquido. } \\
\text { a / f. Resíduos sólidos por kg de } \\
\text { cera. } \\
\text { b / f. Resíduos sólidos por lucro } \\
\text { líquido. } \\
\text { a / g. Consumo de embalagem por } \\
\text { kg de cera. } \\
\text { b / g. Consumo de embalagem por } \\
\text { lucro líquido. } \\
\text { b / h. Consumo de água por lucro } \\
\text { líquido. } \\
\text { a / h. Consumo de água por kg de } \\
\text { cera. }\end{array}$} \\
\hline & $\begin{array}{l}\text { d. Emissões de gases que } \\
\text { contribuem para o efeito de } \\
\text { estufa. }\end{array}$ & \\
\hline & $\begin{array}{l}\text { e. Consumo de materiais: pó } \\
\text { cerífero, solvente, argilas, } \\
\text { peróxido de hidrogênio, palha } \\
\text { de arroz e tecido para o filtro. }\end{array}$ & \\
\hline & $\begin{array}{l}\text { f. Resíduos sólidos: borra (palha } \\
\text { de arroz), barro (argilas e } \\
\text { impurezas) e tecido. }\end{array}$ & \\
\hline & g. Consumo de embalagem. & \\
\hline & h. Consumo de água. & \\
\hline
\end{tabular}

Fonte: Elaboração própria (2004). 


\section{Eco-eficiência na produção de cera de carnaúba}

No Piauí, a literatura tende a apresentar que, após ampliação do grau de diversidade da economia piauiense e depois da segunda Revolução Industrial que impulsionou a expansão de setores químicos, elétricos, automobilísticos e petroquímicos, iniciaram-se os chamados ciclos extrativistas. No final do século XIX, os ciclos extrativistas piauienses foram inaugurados pela maniçoba, arbusto do qual se extrai um látex para a confecção de borracha. Com a perda de competitividade para os asiáticos a atividade da maniçoba entrou em decadência e já, a partir da segunda década do século XX, a cera de carnaúba inicia um novo ciclo econômico para o estado, relegado, a partir de 1950, com o desenvolvimento do ciclo do babaçu.

A cera de carnaúba tornou-se o principal produto na pauta de exportação do Piauí com forte mercado no período da Primeira Guerra Mundial, devido sua importância na produção de explosivos. Chegou a representar $40 \%$ do total da produção da economia brasileira. Na década de 1920, a demanda se ampliou e os altos preços estimularam a produção até o final da década de 1940. O período de 1935 a 1947 marcou o apogeu da cera no mercado mundial, devido à expansão da economia de guerra norte-americana. Com a desaceleração do esforço de guerra, a demanda caiu e, a partir dos anos 50, desenvolveram-se as resinas sintéticas, provocando o declínio da atividade (RIBEIRO, 2001).

O declínio do ciclo da carnaúba não representou o fim da atividade. É importante ressaltar que a cera de carnaúba, apesar de ter passado por oscilações de demanda ao longo do tempo, teve, na verdade, contínua e ampliada participação no mercado. Dados do Anuário Estatístico do Brasil [entre 1920 e 2000] mostram que, particularmente, para o Piauí, a produção de cera, em 1920, estava um pouco acima de 1 mil toneladas. Em 2004, apenas as exportações somaram mais de 5 mil toneladas, representado, o terceiro produto de maior faturamento na pauta das exportações do estado (MDIC, 2005). Infere-se, portanto, crescimento 
na atividade de produção de cera que foi acompanhada por modernização e progresso técnico, constituindo, atualmente, um notável produto dinamizador das exportações piauienses.

Figura 1 - Processo de produção de cera de carnaúba na indústria considerada moderna.

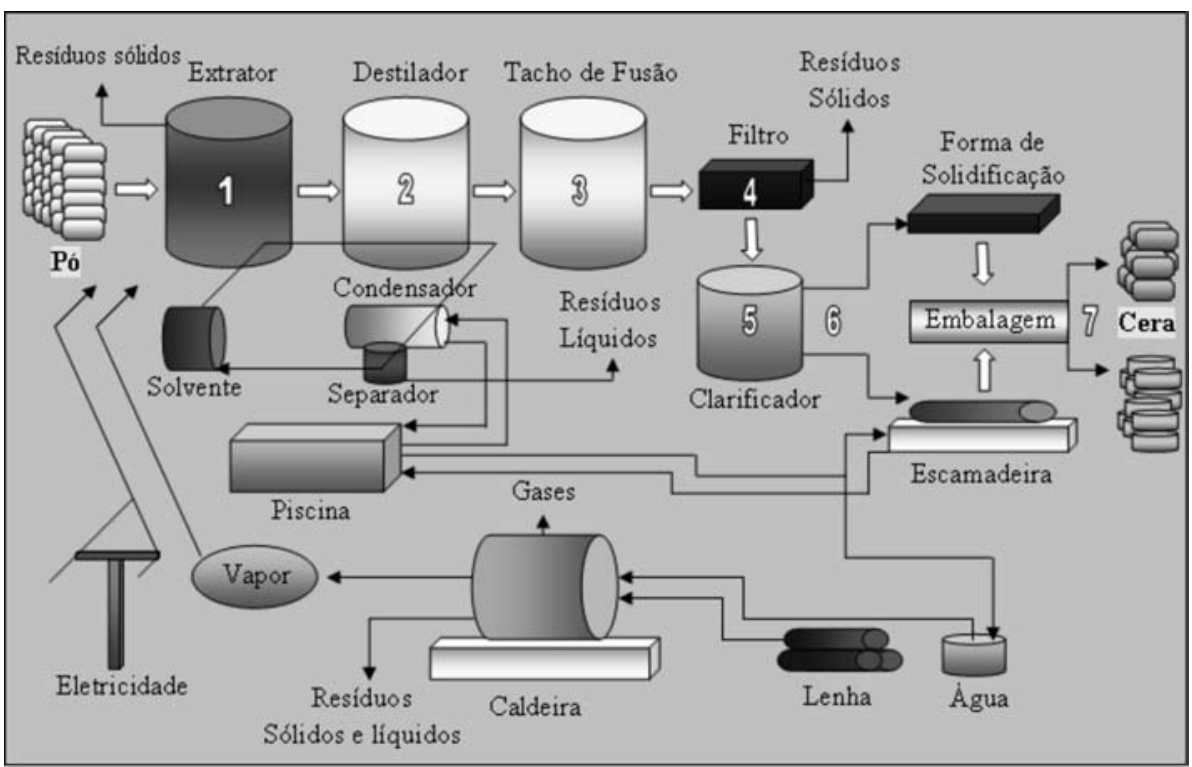

Fonte: Elaboração própria (2004).

O processo de produção de cera apresenta heterogeneidade técnica, persiste a produção artesanal e a produção moderna. Em sua fase inicial, era uma atividade totalmente artesanal/tradicional em que o pó cerífero era processado com a utilização de: forno, prensa, latões, tecido para filtração, água e mão-de-obra.

O processo de produção moderno de cera de carnaúba tem essencialmente sete etapas conforme mostra a Figura 1.

A matéria-prima prima principal da produção de cera, o pó cerífero, passa por teste de qualidade que verifica o grau de pureza e rentabilidade do pó para que seja efetivada a compra, levando em conta a classificação em pó olho e pó palha. O processamento do pó olho ocorre separadamente do pó palha, gerando tipos de cera com diferentes níveis de qualidade. 
1. No Extrator, coloca-se a mistura de pó cerífero, material de drenagem e solvente que passa por um processo de aquecimento numa temperatura que varia entre 100 e $120^{\circ} \mathrm{C}$, gerando um composto de cera fundida, água resultante da perda de umidade e palha de arroz. Os resíduos que ficam são compostos fundamentalmente por palha de arroz e impurezas, são chamados, na indústria, de borra.

2. O Destilador é responsável pela separação da mistura de solvente e água da cera líquida. O solvente e a água evaporam pelo processo de aquecimento para o condensador, ficando a cera líquida retida no fundo do recipiente. No condensador a mistura de solvente e água, é resfriada, voltando ao estado líquido. A água que passou pelo condensador retorna à piscina para ser reaproveitada. A mistura de água e solvente é separada por diferença de densidade, sendo que a água é descartada como resíduo e o solvente retorna para o recipiente original para ser reaproveitado. Segundo o gerente de produção, ao longo de todo o trajeto do solvente há perdas na ordem de $5 \%$.

3. O Tacho de Fusão é o recipiente que recebe a cera líquida do destilador para que sejam adicionadas as argilas usadas na contenção de impurezas e clorofila misturadas ao pó.

4. O Filtro dispõe de paredes de papel fino ou tecido que retém as argilas misturadas às impurezas, permitindo que a cera passe para o processo de clarificação ou siga direto para a escamadeira ou forma de solidificação. Os resíduos liberados do filtro geralmente precisam passar por um outro processo para retirada do restante de cera o gerente de produção afirmou que ficam cerca de $30 \%$ de cera esses resíduos são, também chamados de barro.

5. No Clarificador, adiciona-se na cera peróxido de hidrogênio $\left(\mathrm{H}_{2} \mathrm{O}_{2}\right)$, substância conhecida popularmente por água oxigenada. Neste processo é que se define os tipos de cera: Tipo 1, Tipo 3 e Tipo 4. A cera do Tipo 1 passa pelo processo de clarificação e é originária do olho, tendo melhor preço e qualidade. As ceras do tipo 3 e 4 são originárias das palhas, mas diferem na cor, porque a Tipo 4 não passa pelo processo de clarificação.

6. A cera vai para a Escamadeira, gerando uma fina camada sólida de cera que ao cair no reservatório, quebra-se em pequenos pedaços 
similares à escama de peixe. Quando o mercado exige cera em barra, ela deve ser direcionada ao Tacho de Solidificação em que fica depositada, para esperar um processo natural de resfriamento. Em geral, a maior parte da produção é escamada.

7. A embalagem da cera é realizada, com o auxílio de um operário, em sacos de $25 \mathrm{~kg}$. Estes são fechados, pesados e levados ao depósito para serem distribuídos.

No referido processo, prevalecem mão-de-obra com carteira assinada e condições de trabalho dentro dos padrões de segurança. A indústria tem funcionamento regular durante o ano inteiro, através da acumulação de estoque de pó no período de safra. As indústrias modernas do setor de produção de cera têm, em média, o mesmo padrão técnico e participação na administração de grupos empresariais cearenses.

A produção de cera de carnaúba caracteriza-se por apresentar empresas direcionadas prioritariamente ao mercado externo, sendo beneficiadas através da Lei No 4.859 de 27 de agosto de 1996, atualizada até a Lei $\mathrm{N}^{\circ} 5.177 / 2000$, que dispõe sobre a concessão de incentivos fiscais de dispensa do pagamento do ICMS para empreendimentos industriais e agroindustriais, estabelecidos no estado do Piauí.

Um dos maiores problemas enfrentados pelos produtores é a intermediação das vendas no mercado externo, pois são poucos os corretores que vendem a maior parte da produção para um pequeno número de compradores que distribuem o produto. Assim, criam-se fortes influências dos compradores internacionais com exercício de grande poder de compra, caracterizando uma estrutura de oligopsônio, ou seja, o maior poder de mercado está no comprador. $\mathrm{O}$ fato de a cera ter pouca participação na composição final dos produtos pode agravar essa situação, entretanto, por outro lado, a condição de ser um produto natural dificulta a participação de produtos substitutos próximos, criando uma estrutura semelhante ao monopólio da cera de carnaúba no mercado de cera vegetal.

Apesar da cera ter se sobressaído como o mais dinâmico produto derivado da carnaúba, os demais promovem a melhoria da qualidade de vida das pessoas, seja de forma direta, pelo consumo de bens artesanais, remédios, alimentos e outros, seja indireta, pela geração de emprego e renda. 


\subsection{Elementos e indicadores de eco-eficiência na produção de cera}

No processo industrial de fabricação da cera, identificou-se o impacto ambiental relacionado com: consumo de energia, emissões aéreas, consumo de materiais, resíduos sólidos, consumo de embalagem e consumo de água. Esses impactos foram enquadrados nos sete elementos analisados conjuntamente em quatro seções: consumo de energia e emissão de substâncias tóxicas; consumo de materiais e reciclagem; uso sustentável dos recursos renováveis e durabilidade e agregação de valor. Ao final, examinaram-se indicadores consolidados construídos a partir da razão entre a dimensão de valor da cera, representada pela quantidade de cera produzida e pelo lucro líquido, e dimensão ambiental, correspondente aos indicadores de influencia ambiental na atividade (consumo de energia, água, materiais, embalagens e geração de resíduos sólidos e emissões aéreas).

Quanto à dimensão valor da cera, utilizaram-se dados do ano de 2004, para verificar o nível de produção e lucro líquido. A base da pesquisa, indústria instalada em Campo Maior, tem capacidade produtiva de 2.640,00 toneladas por ano. A quantidade de cera produzida passou de $890.000,00 \mathrm{~kg}$ de cera em 2002, para 1.314 toneladas em 2003 e 1.900 toneladas em 2004. De 2002 a 2004, o crescimento foi de $113,48 \%$ e em 2004 a produção representou uso de $71,97 \%$ da capacidade instalada. A Tabela 1 informa a produção de cera e o lucro líquido estimado.

Tabela 1 - Quantidade produzida e lucro líquido, 2004.

Indicadores de Eco-eficiência

\begin{tabular}{cc|c|c}
\hline & Valor da Cera & Valor & Unidade \\
\hline A & Quantidade Produzida & $1.900 .000,00$ & $\mathrm{Kg}$ \\
B & Lucro líquido & $5.771 .250,00$ & $\mathrm{R} \$$ \\
\hline
\end{tabular}

Fonte: Pesquisa direta (2004).

Esse processo gerou 30 empregos diretos distribuídos entre operários, gerente, técnicos, recepcionistas e vigia. Demandou 2.968.750,00 kg 
de pó cerífero e outros materiais como peróxido de hidrogênio, argilas, palha de arroz, solvente e tecidos para filtros. O nível de utilização desses recursos e o efeito ao meio ambiente são abordados a seguir.

\subsubsection{Consumo de energia e emissão de substâncias tóxicas}

O consumo de energia na produção de cera teve como fonte básica a lenha, a eletricidade e o óleo diesel combustível. Esse consumo foi, também, o principal meio de emissão de substâncias que podem contribuir potencialmente para o aquecimento global e outros problemas ambientais.

A lenha utilizada na caldeira para gerar calor, adveio da mata nativa local, a qual enquadra-se em região ecotonal, ou seja, uma área de transição vegetacional em que há a predominância de espécies típicas dos biomas cerrado e caatinga. Apesar da lenha ser um produto renovável, o seu consumo pode gerar implicações ambientais na medida em que a retirada da cobertura vegetal nativa, sem a aplicação de um manejo adequado, pode trazer prejuízos ao ecossistema, como perda de espécies, fragmentação da vegetação - isolamento de áreas sem corredores ecológicos - e outros. Deve-se ressaltar que o grau de agressão à natureza depende da forma de exploração e da intensidade de uso dessas matas para formação de lenha. A pesquisa direta revelou que o IBAMA fiscaliza, freqüentemente, junto à empresa o consumo da lenha.

O diesel combustível é uma fonte não renovável de energia que gera impactos na sua produção, distribuição e consumo. A queima do diesel ocorreu na produção de cera, pelo uso de uma carreta e um caminhão no transporte de insumos, essencialmente, o pó cerífero, quando a empresa buscou-o nas regiões adjacentes e, no transporte da cera.

O consumo de eletricidade, aparentemente, não gera impacto ambiental, entretanto, seu o uso gera emissão de $\mathrm{CO}_{2}$, contribuindo para o aquecimento global. Deve-se considerar, no entanto, que em geral, a eletricidade é uma das fontes de energia mais limpa existente e, além disso, é renovável.

A Tabela 2 apresenta o consumo de energia para o processo de produção de cera, perfazendo um total de 132.607,88 TWh de energia relacionado ao consumo de lenha, óleo diesel combustível e eletricidade. 
Tabela 2 - Consumo de energia, 2004.

\begin{tabular}{lc|c|c|c}
\hline \multicolumn{4}{c}{ Indicadores de Eco-eficiência } \\
\hline \multicolumn{2}{c}{ Influência Ambiental } & Valor & Unidade & $\%$ \\
\hline C & Consumo de energia & $\mathbf{1 3 2 . 6 0 7 , 8 8}$ & TWh & $\mathbf{1 0 0 , 0 0}$ \\
$\mathbf{c}_{1}$ & Lenha & $127.992,93$ & TWh & 96,52 \\
$\mathbf{c}_{2}$ & Diesel & $4.614,95$ & TWh & 3,48 \\
$\mathbf{c}_{\mathbf{3}}$ & Eletricidade & 0,000192 & TWh & 0,00 \\
\hline
\end{tabular}

Fonte: Pesquisa direta (2004).

Do total de energia consumida, a maior parte foi de energia oriunda da lenha, 127.992,93 TWh (96,52 \%). O diesel representou 3,48 \% do consumo de energia e a eletricidade, 192.000,00 kWh, representou apenas 0,000192 TWh de energia. O impacto do consumo de lenha e diesel é progressivamente danoso, pois emitem substâncias nocivas à saúde humana, animal e vegetal, em quantidade substancialmente maior que a energia elétrica.

A energia produzida pela lenha deu-se pelo consumo de $4.800,00$ $\mathrm{m}^{3}$ ou $2.928 .000 \mathrm{~kg}$, considerando a densidade de $0,61 \mathrm{~g} / \mathrm{cm}^{3}$ e o poder calorífero de $2.898,00 \mathrm{kcal} / \mathrm{kg}$, referenciado em Vale et. al. (2003). A energia oriunda do diesel refere-se ao consumo de 33.750 litros de diesel consumidos em 2004, que correspondeu a 28.481,01 kg (fator 1.185 litros por toneladas). O poder calorífero do diesel é de 45,01 GJ/t, referenciado em UNCTAD (2004).

As emissões provocadas pela queima da lenha têm referência em Ministério da Ciência e Tecnologia (MCT, 2005) que apresenta fator de emissões da lenha, 29,9 t C/TJ. Como este fator não expressou a equivalência em $\mathrm{CO}_{2}$, utilizou-se o fator de conversão de "peat briquettes" (massa de carvão de turfa), citado em UNCTAD (2004) que teve o nível de emissão de 25,8 t C/TJ, próximo da lenha, representando 94,6 t $\mathrm{CO}_{2}$ / TJ. As emissões provocadas pelo diesel foram calculadas referenciando 
UNCTAD (2004), que destacou o fator de conversão para o diesel na ordem de 74,07 toneladas de $\mathrm{CO}_{2}$ por $\mathrm{TJ}$ de energia usada e, as emissões provocadas pela energia elétrica estão referenciadas em UNCTAD (2004) como 0,000057 t CO$/ 2$ kW.

Tabela 3 - Emissões provocadas pelo consumo de lenha, diesel e eletricidade, 2004.

Indicadores de Eco-eficiência

\begin{tabular}{cc|c|c|c}
\hline & Influência Ambiental & Valor & Unidade & $\%$ \\
\hline $\mathbf{D}$ & Emissões de $\mathbf{C O}_{2}$ & $\mathbf{3 . 4 7 0 . 5 3 0 , 9 0}$ & $\mathbf{k g}$ & $\mathbf{1 0 0 , 0 0}$ \\
$\mathrm{d}_{1}$ & Lenha & $3.364 .634,33$ & $\mathrm{~kg}$ & 96,95 \\
$\mathrm{~d}_{2}$ & Diesel & $94.952,57$ & $\mathrm{~kg}$ & 2,74 \\
$\mathrm{~d}_{3}$ & Eletricidade & $10.944,00$ & $\mathrm{~kg}$ & 0,32 \\
\hline
\end{tabular}

Fonte: Pesquisa direta (2004).

A maior parte das emissões, $96,95 \%$ foi provocada pelo consumo de lenha, que lançou 3.364,63 toneladas de $\mathrm{CO}_{2}$ em 2004. A combustão do diesel, além da emissão de $\mathrm{CO}_{2}$, lança outras substâncias como $\mathrm{NO}_{x}$ e $\mathrm{SO}_{2}$ que contribuem para chuva ácida, mas esse consumo foi relativamente pequeno em relação ao consumo de lenha, apenas $2,74 \%$ das emissões. A eletricidade contribuiu com apenas $0,32 \%$ das emissões.

O efeito dessas emissões da lenha pode ter sido reduzido pela presença da biomassa nativa que deve ter absorvido grande parte das emissões, tendo em vista que a indústria não se encontra em área urbanizada, está aproximadamente a uma distância de $7 \mathrm{~km}$ do perímetro urbano. Detectou-se, ainda, um sistema de contenção da poluição gerada pela queima da lenha, chamado de "lavador de fumaça” que gera uma chuva sobre a fumaça. A localização da indústria fora do perímetro urbano facilitou, também, a absorção 
das emissões provocadas pela eletricidade, assim, a concentração de gases e, portanto, o possível efeito sobre o aquecimento global pode ter sido reduzido.

Quanto ao consumo de diesel, o transporte deu-se a longas distâncias o que contribuiu para aumentar o consumo e, portanto, agravar problemas ambientais, entretanto, os maiores trechos das rodovias não estão em perímetros urbanos o que evitou a concentração de gases e facilitou a absorção das emissões pela mata à margem da pista, mas nem todas as substâncias podem ser absorvidas e de qualquer forma, as emissões provocadas pelo diesel contribuem para agravar problemas ambientais.

Uma das medidas que poderiam ser tomadas para reduzir o impacto do uso da lenha seria a troca dessa fonte energética por outra menos danosa ao ecossistema como uso de bagaço de cana, em que se deixaria de utilizar a mata nativa, ou o uso de biodiesel. A indústria já dispõe de plantio de cana irrigado pela água não mais utilizada no processo industrial, então, seria possível utilizar esses materiais como incremento substitutivo da lenha progressivamente, pelo aumento do plantio. O diesel poderia, também, ser trocado por biodiesel que é um produto renovável e menos poluente.

\subsubsection{Consumo de materiais e reciclagem}

Os materiais consumidos na produção de cera são: pó cerífero, palha de arroz, solvente, argilas, peróxido de hidrogênio e tecido para o filtro.

O pó cerífero é a matéria-prima básica da cera, é um produto natural renovável que provém do corte das folhas da carnaubeira e sua produção de pó não gera grandes impactos ambientais.

A palha de arroz é um sub-produto do arroz que geralmente é descartado como resíduo, servindo como adubo. Na produção de cera é usado como facilitador de drenagem do pó. É um material natural, não tóxico, biodegradável e renovável. Depois de seu processamento na produção de cera é destinado para adubação.

O solvente é um produto químico tóxico e gera impacto importante a natureza e ao homem. O solvente utilizado é tipo ISSOL 80-155, com densidade média de $0,7225 \mathrm{~g} / \mathrm{cm}^{3}\left(20^{\circ}-4^{\circ} \mathrm{C}\right)$. No processo de 
produção de cera, não houve contato direto desse produto com o ser humano. A maior parte de seu consumo ocorreu pela perda no processo de aquecimento nos extratores e no seu resfriamento no condensador, para que retorne ao tanque original e seja reaproveitado.

As argilas são usadas para auxiliar na filtração. Consumiram-se dois tipos na produção de cera: 1. Diatomita que tem como composição básica $\left(\mathrm{SiO}_{2}\right.$ de 81 - $\left.93 \%\right)$ é um produto classificado como não perigoso, estável, não inflamável, explosivo ou tóxico; 2. Tonsil, também, tem em sua composição essencialmente $\left(\mathrm{SiO}_{2}\right.$ de 61 - 71\%), é incombustível e não tóxico, quanto a reatividade é estável e inerte. Geralmente ficam $30 \%$ de cera no resíduo que sai do filtro, composto em sua maioria por argilas e impurezas, por isso, esse resíduo retorna aos extratores para retirada do restante de cera em um novo processamento. Depois do processo de fabricação de cera o resíduo do filtro é, também, usado na adubação.

$\mathrm{O}$ peróxido de hidrogênio $\mathrm{H}_{2} \mathrm{O}_{2}(60 \%)$ é oxidante e corrosivo e não inflamável. No processo, ele é adicionado à cera aquecida para o clareamento, o que pode gerar emissões. Não há lançamento ao solo e/ou cursos de água.

O tecido filtro é um material utilizado apenas uma vez no processo de filtragem, é um tecido comum de algodão que tem um acabamento rústico.

A maior parte dos materiais utilizados é natural, renovável, não perigoso e biodegradável. Portanto, podem contribuir para o elemento "Maximização do uso sustentável dos recursos naturais".

A Tabela 4 indica o consumo de materiais para o processo de produção de cera, em 2004.

A maior parte do consumo de materiais foi de pó cerífero o insumo básico de fabricação da cera representando 81,62\% de todos os materiais usados na produção de cera. A palha de arroz foi o segundo material mais utilizado, representando $11,79 \%$ de todo o consumo. O peróxido de hidrogênio não é reaproveitado, entretanto utiliza-se um percentual pequeno $(3,55 \%)$ em relação ao consumo total de materiais. O solvente apresenta um baixo consumo em decorrência de sua reutilização. As argilas representando $1,11 \%$ de todo o consumo de materiais, ainda, têm utilização para adubação e o tecido filtro é descartado não sendo mais reaproveitado no processo. 
Tabela 4 - Consumo de materiais, 2004.

\begin{tabular}{|c|c|c|c|c|}
\hline \multicolumn{5}{|c|}{ Indicadores de Eco-eficiência } \\
\hline & Influência Ambiental & Valor & Unidade & $\%$ \\
\hline $\mathbf{E}$ & Consumo de materiais & $3.637 .158,00$ & kg & 100,00 \\
\hline $\mathrm{e}_{1}$ & Pó cerífero & $2.968 .750,00$ & $\mathrm{~kg}$ & 81,62 \\
\hline $\mathrm{e}_{2}$ & Palha de arroz & $428.984,00$ & $\mathrm{~kg}$ & 11,79 \\
\hline $\mathrm{e}_{3}$ & Peróxido de hidrogênio & $129.200,00$ & $\mathrm{~kg}$ & 03,55 \\
\hline $\mathrm{e}_{4}$ & Solvente & $68.637,50$ & $\mathrm{~kg}$ & 01,89 \\
\hline$e_{5}$ & Argilas & $40.375,00$ & $\mathrm{~kg}$ & 01,11 \\
\hline $\mathrm{e}_{6}$ & Tecido filtro & $1.211,25$ & $\mathrm{~kg}$ & 00,03 \\
\hline
\end{tabular}

Fonte: Pesquisa direta (2004).

As argilas além de serem reaproveitadas em uma segunda fase na retirada do restante de cera podem ser jogadas ao solo, pois se deterioram naturalmente. A palha de arroz mesmo sendo usada apenas uma vez, funciona como um bom adubo, portanto, dos materiais que podem ser reaproveitados, a grande maioria o é, contribuindo, assim, para “intensificação da reciclagem de materiais”. A Tabela 5 mostra os resíduos gerados na produção de cera.

Do total de resíduos emitidos, $71,41 \%$ foram barro, formado fundamentalmente por argilas e impurezas contidas no pó de carnaúba, outros $29,58 \%$ foram borra, composto essencialmente por palha de arroz e, apenas 0,08\% foi tecido. Desses resíduos, apenas o tecido tem problemas na deterioração natural que pode levar um tempo substancial, os demais são biodegradáveis, renováveis e com utilização em outros processos. 
Tabela 5 - Geração de resíduos sólidos, 2004.

\begin{tabular}{cc|c|c|c}
\hline \multicolumn{5}{c}{ Indicadores de Eco-eficiência } \\
\hline \multicolumn{2}{c}{ Influência Ambiental } & Valor & Unidade & $\%$ \\
\hline F & Resíduos sólidos & $\mathbf{1 . 4 5 0 . 2 5 7 , 7 5}$ & $\mathbf{k g}$ & $\mathbf{1 0 0 , 0 0}$ \\
$\mathrm{f}_{1}$ & Barro & $1.020 .062,5$ & $\mathrm{~kg}$ & 70,34 \\
$\mathrm{f}_{2}$ & Borra & $428.984,00$ & $\mathrm{~kg}$ & 29,58 \\
$\mathrm{f}_{3}$ & Tecido filtro & $1.211,25$ & $\mathrm{~kg}$ & 0,08 \\
\hline
\end{tabular}

Fonte: Pesquisa direta (2004).

Uma questão importante a ser ressaltada é quanto ao consumo de embalagens. Todas as embalagens que chegam na indústria acondicionando o pó cerífero retornam para o vendedor.

As embalagens usadas para empacotar a cera são formadas por um material plástico resistente e não é reaproveitada no processo; é, portanto, um produto descartado no consumo da cera e que deve ser dotado de um manejo adequado para não gerar problemas ambientais. A Tabela 6 apresenta o consumo desse tipo de embalagem na produção de cera, um consumo relativamente pequeno: foram apenas 11.400,00 kg de embalagens para acondicionar 1.900 toneladas de cera.

Tabela 6 - Consumo de embalagens, 2004.

Indicador de Eco-eficiência

\begin{tabular}{llc|c}
\hline & Influência Ambiental & Valor & Unidade \\
\hline G Consumo de Embalagens & $11.400,00$ & $\mathrm{~kg}$ \\
\hline
\end{tabular}

Fonte: Pesquisa direta (2004). 
O amplo grau de materiais naturais utilizados nesse processo é um bom indicativo para a atividade, e a reutilização pode contribuir para o elemento "Redução do consumo de materiais" e de uma forma indireta, para "Agregação de valor" pois produtos associados à redução de impacto ao meio ambiente encontram maior valor de mercado.

Algumas medidas de redução de impacto quanto ao uso de materiais seria a contenção na geração de poluentes e aumento da produtividade na produção do pó cerífero, que é o principal material utilizado, e maior otimização nos demais processos como, por exemplo, a reutilização da palha, não em outros processos, mas sim na fabricação de cera, e, maior eficiência na reciclagem do solvente.

\subsubsection{Uso sustentável de recursos renováveis}

A produção de cera mostra certo grau de sustentabilidade ao usar em sua maioria, materiais e energias renováveis. O consumo de energia elétrica e energia derivada da lenha somam a maior parte da energia consumida e ambas são renováveis.

O pó cerífero e a palha de arroz que somam juntas 93,41\% de todos os materiais utilizados na produção de cera são produtos naturais e renováveis, portanto, há uma maximização de uso de insumos renováveis. Como se detectou, o pó cerífero é usado apenas uma vez no processo, mas a palha de arroz (borra) que corresponde a 29,58\% de todo o peso dos resíduos sólidos gerados é aproveitada em outros processos, especialmente na adubação. A atividade de produção cera, em geral, maximiza o uso sustentável de recursos renováveis.

Uma questão preocupante é quanto ao consumo da água. A água de abastecimento é um tema global e indispensável para a manutenção da vida, um recurso cada vez mais escasso.

O consumo de água (Tabela 7) ocorre pelo resfriamento da cera na escamadeira, resfriamento do solvente no condensador e no uso de água na caldeira que responde por quase metade do consumo em que se faz o processo de vaporização, e redução dos poluentes emitidos da fumaça no "lavador de fumaça”. Ocorrem perdas por evaporação quando a água retorna à piscina. 
Tabela 7 - Consumo de água, 2004.

\begin{tabular}{|c|c|c|}
\hline \multicolumn{3}{|c|}{ Indicador de Eco-eficiência } \\
\hline Influência Ambiental & Valor & Unidade \\
\hline H Consumo de Água & 20.16 & 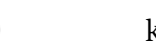 \\
\hline
\end{tabular}

Fonte: Pesquisa direta (2004).

É importante ressaltar que grande parte desse consumo refere-se ao desperdício que ocorre na limpeza dos recipientes, em que a água é lançada ao solo. Em 2004, esse desperdício correspondeu a aproximadamente $10 \%$ de todo o consumo de água. Essa água não é poluída com qualquer tipo de produto químico ou tóxico e pode ser facilmente reutilizada.

É necessário reduzir o nível de desperdício e tomarem-se medidas para o melhor uso da água, tais como, o uso da água que sai do condensador, pela perda de umidade dos materiais, para o resfriamento e reaproveitamento; mudanças na técnica de retorno da água à piscina poderiam reduzir o consumo; a construção de um tanque para receber a água quente que retorna do processo industrial, até que ocorresse o processo natural de resfriamento; e a construção de um tanque reserva para acondicionar a água no processo de limpeza da piscina e uso de produtos de limpeza da água quando necessário.

\subsubsection{Durabilidade e agregação de valor}

A cera é um produto intermediário, entra na composição de outros produtos, é não perecível e de validade indeterminada. Sua propriedade fundamental é ampliar a durabilidade e agregar valor em produtos. Pesquisa sobre conservação do tomate com cera de carnaúba premiou a estudante Marcela Chiumarelli da Faculdade de Engenharia Agrícola da UNICAMP, que ganhou o Prêmio Jovem Cientista do CNPq em 2004. Seu trabalho mostra que frutas perecíveis, quando protegidas por cera de carnaúba, ampliam significativamente sua durabilidade. A cera é 
um importante isolante térmico, um produto natural que não gera problemas à saúde humana e amplia a qualidade dos produtos que ela auxilia na composição.

A agregação de valor na cera depende da ampliação de melhorias qualitativas, possíveis com mudanças nos insumos, processos e técnicas de maneira que expanda a satisfação do consumidor com um produto de maior funcionalidade. A redução de materiais por cera fabricada, medidas de contenção de poluição e, mudanças em processos e técnicas que gerem ganhos de produtividades elevariam o valor agregado. As qualidades naturais dos vários materiais já elevam a qualidade da cera e, portanto auxiliam na agregação de valor.

\subsubsection{Indicadores de eco-eficiência consolidados}

Os indicadores de eco-eficiência consolidados mostram a razão entre duas dimensões, valor da cera e influência ambiental. O valor da cera foi representado pela quantidade de cera produzida (A) e lucro líquido (B) e a influência ambiental pelos indicadores, consumo de energia (C), emissões aéreas (D), consumo de materiais (E), geração de resíduos sólidos $(\mathrm{F})$, consumo de embalagens $(\mathrm{G})$ e consumo de água $(\mathrm{H})$ (Tabela 8).

Em consumo de energia, o Indicador consolidado 1, mostra que cada TWh de energia usada gerou $14,33 \mathrm{~kg}$ de cera. Das fontes de energia utilizadas, a que se mostrou amplamente eficiente foi a energia elétrica e a menor foi a energia oriunda da lenha, que cada TWh de energia consumida criou $14,84 \mathrm{~kg}$ de cera. O diesel apresentou um grau de eficiência substancialmente maior que a lenha, $411,71 \mathrm{~kg}$ de cera para cada TWh de energia gasta. Isso significa que cada litro de diesel gerou 56,30 kg de cera; já a lenha, cada $\mathrm{m}^{3}$ queimado gerou 395,86 kg. O Indicador consolidado 2 exibe que cada TWh de energia criou $\mathrm{R} \$ 43,52$ de lucro líquido, evidenciando a mesma tendência observada no Indicador consolidado 1, a energia elétrica contribuiu significantemente para a formação de lucro e a lenha deu a menor contribuição. 
Tabela 8 - Indicadores de eco-eficiência consolidados na produção de cera, 2004.

\begin{tabular}{|c|c|c|c|c|c|c|c|}
\hline \multirow{2}{*}{\multicolumn{2}{|c|}{$\begin{array}{c}\text { Indicadores de } \\
\text { Eco-eficiência }\end{array}$}} & \multicolumn{3}{|c|}{ Indicador Consolidado 1} & \multicolumn{3}{|c|}{ Indicador Consolidado 2} \\
\hline & & Fórmula & Valor & Unidade & Fórmula & Valor & Unidade \\
\hline C & $\begin{array}{c}\text { Consumo de } \\
\text { energia }\end{array}$ & $A \div C$ & 14,33 & kg/TWh & $B \div C$ & 43,52 & $\mathrm{R} \$ / \mathrm{TWh}$ \\
\hline $\mathrm{c}_{1}$ & Lenha & $A \div c_{1}$ & 14,84 & $\mathrm{~kg} / \mathrm{TWh}$ & $\mathrm{B} \div \mathrm{c}_{1}$ & 30,06 & $\mathrm{R} \$ / \mathrm{TWh}$ \\
\hline $\mathrm{c}_{2}$ & Diesel & $A \div c_{2}$ & 411,71 & $\mathrm{~kg} / \mathrm{TWh}$ & $B \div c_{2}$ & $1.250,56$ & $\mathrm{R} \$ / \mathrm{TWh}$ \\
\hline $\mathrm{c}_{2}$ & Eletricidade & $A \div c_{2}$ & $9.895 .833 .333,33$ & kg/TWh & $B \div c_{2}$ & $30.058 .593 .750,00$ & $\mathrm{R} \$ / \mathrm{TWh}$ \\
\hline $\mathbf{D}$ & Emissões & $A \div D$ & 0,55 & $\mathrm{~kg} / \mathrm{kg}$ & B $\div$ D & 1,66 & $\mathrm{R} \$ / \mathrm{kg}$ \\
\hline$d_{1}$ & Lenha & $A \div d_{1}$ & 0,56 & $\mathrm{~kg} / \mathrm{kg}$ & $B \div d_{1}$ & 1,72 & $\mathrm{R} \$ / \mathrm{kg}$ \\
\hline$d_{2}$ & Diesel & $A \div d_{2}$ & 20,01 & $\mathrm{~kg} / \mathrm{kg}$ & $B \div d_{2}$ & 60,78 & $\mathrm{R} \$ / \mathrm{kg}$ \\
\hline$d_{3}$ & Eletricidade & $A \div d_{3}$ & 173,61 & $\mathrm{~kg} / \mathrm{kg}$ & $B \div d_{3}$ & 527,34 & $\mathrm{R} \$ / \mathrm{kg}$ \\
\hline $\mathbf{E}$ & $\begin{array}{c}\text { Consumo de } \\
\text { materiais }\end{array}$ & $\mathbf{A} \div \mathbf{E}$ & 0,52 & $\mathrm{~kg} / \mathrm{kg}$ & $B \div E$ & 1,59 & $\mathbf{R} \$ / \mathbf{k g}$ \\
\hline $\mathbf{e}_{1}$ & Pó cerífero & $A \div \mathbf{e}_{1}$ & 0,64 & $\mathrm{~kg} / \mathrm{kg}$ & $B \div \mathrm{e}_{1}$ & 1,94 & $\mathrm{R} \$ / \mathrm{kg}$ \\
\hline $\mathbf{e}_{2}$ & $\begin{array}{l}\text { Palha de } \\
\text { arroz }\end{array}$ & $A \div \mathbf{e}_{2}$ & 4,43 & $\mathrm{~kg} / \mathrm{kg}$ & $B \div e_{2}$ & 13,45 & $\mathrm{R} \$ / \mathrm{kg}$ \\
\hline $\mathbf{e}_{3}$ & Solvente & $A \div \mathbf{e}_{3}$ & 27,68 & $\mathrm{~kg} / \mathrm{kg}$ & $B \div \mathbf{e}_{3}$ & 84,08 & $\mathrm{R} \$ / \mathrm{kg}$ \\
\hline $\mathbf{e}_{4}$ & Argilas & $A \div \mathbf{e}_{4}$ & 47,06 & $\mathrm{~kg} / \mathrm{kg}$ & B $\div \mathrm{e}_{4}$ & 142,94 & $\mathrm{R} \$ / \mathrm{kg}$ \\
\hline $\mathbf{e}_{5}$ & $\begin{array}{l}\text { Peróxido de } \\
\text { hidrogênio }\end{array}$ & $A \div \mathbf{e}_{5}$ & 14,71 & $\mathrm{~kg} / \mathrm{kg}$ & $B \div \mathbf{e}_{5}$ & 44,67 & $\mathrm{R} \$ / \mathrm{kg}$ \\
\hline$e_{6}$ & Tecido filtro & $A \div e_{6}$ & $1.568,63$ & $\mathrm{~kg} / \mathrm{kg}$ & $B \div \mathbf{e}_{6}$ & $4.764,71$ & $\mathrm{R} \$ / \mathrm{kg}$ \\
\hline $\mathbf{F}$ & $\begin{array}{l}\text { Resíduos } \\
\text { sólidos }\end{array}$ & $A \div F$ & 1,31 & $\mathrm{~kg} / \mathrm{kg}$ & $B \div F$ & 3,98 & $\mathbf{R} \$ / \mathbf{k g}$ \\
\hline $\mathrm{f}_{1}$ & Barro & $A \div \mathrm{f}_{1}$ & 1,86 & $\mathrm{~kg} / \mathrm{kg}$ & $B \div f_{1}$ & 5,66 & $\mathrm{R} \$ / \mathrm{kg}$ \\
\hline $\mathrm{f}_{2}$ & Borra & $A \div \mathrm{f}_{2}$ & 4,43 & $\mathrm{~kg} / \mathrm{kg}$ & $B \div f_{2}$ & 13,45 & $\mathrm{R} \$ / \mathrm{kg}$ \\
\hline $\mathbf{f}_{3}$ & Tecido filtro & $A \div \mathrm{f}_{3}$ & $1.568,63$ & $\mathrm{~kg} / \mathrm{kg}$ & $B \div f_{3}$ & $4.764,71$ & $\mathrm{R} \$ / \mathrm{kg}$ \\
\hline G & $\begin{array}{l}\text { Consumo de } \\
\text { Embalagens }\end{array}$ & $A \div \mathbf{G}$ & 166,67 & $\mathrm{~kg} / \mathrm{kg}$ & $B \div \mathbf{G}$ & 506,25 & $\mathrm{R} \$ / \mathrm{kg}$ \\
\hline $\mathbf{H}$ & $\begin{array}{c}\text { Consumo de } \\
\text { Água }\end{array}$ & $A \div \mathbf{H}$ & 0,09 & $\mathrm{~kg} / \mathrm{kg}$ & $B \div \mathbf{H}$ & 0,29 & $\mathrm{R} \$ / \mathrm{kg}$ \\
\hline
\end{tabular}

Fonte: Pesquisa direta (2004). 
O Indicador consolidado 1 de 0,55 referente às emissões mostra que a produção de cera contribui potencialmente para o efeito estufa, pois cada $\mathrm{kg}$ de $\mathrm{CO}_{2}$ emitido relacionou-se a produção de apenas 0,55 kg de cera. $\mathrm{O}$ indicador de maior eficiência foi a eletricidade que cada $\mathrm{kg}$ de $\mathrm{CO}_{2}$ emitido correspondeu a 173,61 kg de cera produzido, e o menor foi a lenha que gerou apenas $0,56 \mathrm{~kg}$. A relação entre formação de lucro e cera produzida no Indicador consolidado 2 destaca um baixo indicador, 1,66 kg / kg, ou seja, cada kg de emissão favoreceu a produção de 1,66 $\mathrm{kg}$ de cera.

Quanto ao consumo de materiais, o Indicador consolidado 1, informa que cada $\mathrm{kg}$ de material fabricou apenas $0,52 \mathrm{~kg}$ de cera, revela grande consumo de materiais por unidade de produto gerada. Dos materiais utilizados o que tem maior eficiência é o tecido filtro em que cada kg filtrou $1568,63 \mathrm{~kg}$ de cera e o menor foi o pó cerífero em que cada $\mathrm{kg}$ gerou apenas $0,64 \mathrm{~kg}$ de cera. A palha de arroz teve relativamente baixa eficiência, cada $\mathrm{kg}$ de palha de arroz fez 4,43 kg de cera. Para cada kg de argila utilizada fabricou-se 47,06 kg de cera, para cada kg de solvente criou 27,68 kg e para cada kg de peróxido de hidrogênio teve-se $14,71 \mathrm{~kg}$ de cera, ou seja, esses materiais tiveram relativa eficiência. Esse indicador reflete, relativamente, o grau de pressão sobre recursos naturais da atividade de produção de cera. É uma referência importante para balizar tomadas de decisões que promovam a redução no consumo de recursos. O Indicador consolidado 2 mostra que os materiais geram baixo lucro líquido por cera produzida, cada kg de material consumido gerou apenas $\mathrm{R}$ 1,59 de lucro líquido para a atividade. O mais eficiente economicamente foi o tecido filtro e o menos, o pó cerífero.

Nos resíduos sólidos, o Indicador consolidado 1 destaca que para cada kg de resíduo gerado fez-se 1,31 kg de cera, sendo que o resíduo que mostra maior eficiência é o tecido filtro e o menor é o barro. O Indicador consolidado 2 mostra relativa eficiência econômica em relação à geração de resíduos, pois para cada kg de resíduo gerado conseguiu-se um lucro líquido de $\mathrm{R} \$ 3,98$. Como cada processo de produção gera de alguma forma resíduo, é importante que esses sejam pelo menos, eficientes, ou seja, utilize-se o mínimo e propicie o máximo de valor 
agregado, além de não serem tóxicos e/ou prejudiquem o meio de alguma forma. Os resíduos sólidos do processo de produção de cera, em sua maioria, são reaproveitados. O único que não é reaproveitado é o tecido filtro, entretanto, ele apresenta grande eficiência.

O consumo de embalagem, apresenta eficiência, pois o Indicador consolidado 1, demonstra que para cada kg de embalagem usada fabricam-se 166,67 kg de cera e, o Indicador consolidado 2 , revela que cada $\mathrm{kg}$ de embalagem propicia $\mathrm{R} \$ 506,25$ de lucro líquido. Esse indicador implica em baixa pressão sobre os recursos naturais quando comparado com os demais indicadores.

O consumo de água é um indicador preocupante, pois revela intenso uso de água por kg de cera produzida. O Indicador consolidado 1, expõe que cada kg de água gera apenas $0,09 \mathrm{~kg}$ de cera e o Indicador consolidado 2 diz que cada $\mathrm{kg}$ de água gera apenas $\mathrm{R} \$ 0,29$ de lucro líquido. Deve-se, portanto, tomar-se medidas de contenção do uso de água.

Infere-se que a co-responsabilidade empresarial sobre as questões ambientais não se configura de forma simples. A variável ambiental nas empresas surge como uma forma estratégica para manutenção e perpetuação no mercado devido a exigências sociais. Portanto, a ecoeficiência é uma vertente prática importante para apoiar as tomadas de decisões nas empresas que absorvem a questão ambiental. É possível perceber que as medidas de contenção de problemas ambientais e racionalização sobre os recursos podem garantir a continuidade, economicamente lucrativa, de uma empresa.

Por outro lado, a eco-eficiência é um conceito atenuador, na vertente ambiental, dos problemas que afetam o modelo de desenvolvimento. Tem fundamental importância para os empresários na medida em que pode, quando incorporado como premissa na empresa, ampliar competitividade ao mesmo tempo em que traz melhorias ambientais e a qualidade de vida para a sociedade.

\section{Considerações finais}

Os processos produtivos sempre geraram resíduos. As reutilizações desses resíduos existem desde quando a produção de mercadorias se desenvolveu, mas a redução do ciclo de vida dos produtos, com adoção, 
cada vez mais intensa, de descartáveis em curto período de tempo, associada à generalização de demandas promovidas pela expansão do capital, elevaram o grau de pressão sobre a natureza e ampliaram desperdícios e externalidades negativas ao meio ambiente. Essas questões impulsionaram ações sociais e de governo reativas, impondo às empresas reduzir a demanda sobre os recursos naturais e eliminar emissões de efluentes e resíduos sólidos ou líquidos, danosos ao meio ambiente e à saúde humana, especificamente.

A noção de eco-eficiência contribui para mudança de conduta nas empresas, pois, amplia as medidas de racionalização de processos e produtos com menores agressões ao meio ambiente. Alavanca de forma direta e indireta melhorias na qualidade de vida das pessoas.

A incorporação da eco-eficiência como um princípio fundamental da gestão estratégica empresarial precisa ser ampliada em todos os segmentos produtivos, independente da dimensão do negócio. As organizações empresariais têm papel fundamental na articulação e disseminação da eco-eficiência e a sociedade, de forma geral, necessita, através de suas instituições, disseminar, apoiar e exigir condutas eco-eficientes, transformando os negócios em eco-negócios.

A produção industrial de cera de carnaúba apresenta, em relação ao consumo de energia, grande uso de lenha e relativo consumo de diesel que favorecem a emissão de substâncias que contribuem potencialmente para o efeito estufa, no entanto, mostra um amplo grau de eficiência no uso de energia elétrica. Apesar de utilizar muitos materiais e formar grande quantidade de resíduo, esses materiais em sua maioria são renováveis e de baixo impacto ambiental. As embalagens mostraram amplo grau de eficiência e o grande consumo de água prejudica a eficiência na produção de cera, sendo, portanto necessário, medidas de contenção no uso de água. Por outro lado, outros fatores atuam amenizando esses impactos negativos, tais como: localização da indústria em área pouco urbanizada; possibilidade de fácil reaproveitamento da água, pois esta não está contaminada.

O processo de produção de cera impacta o meio ambiente com uso intenso de água, utilização da lenha como fonte energética, consumo de produtos químicos e emissão de poluentes, entretanto, atende importantes elementos de eco-eficiência como a reutilização de materiais e 
consumo de materiais renováveis, apresentando, em geral, certo grau de eficiência ambiental.

Entretanto, não existe uma regra fechada para tornar uma empresa eco-eficiente. A sociedade e os empresários construíram práticas e acumularam experiências que direcionam medidas amenizadoras e/ou que eliminam geração de problemas ambientais e, por conseguinte, trazem melhorias econômicas. Cada empreendimento tem suas especificidades quanto ao grau de agressão à natureza, por isso, as ações eco-eficientes dependem de cada estrutura na qual a empresa se insere.

\section{Referências Bibliográficas}

ALMEIDA, F. O bom negócio da sustentabilidade. Rio de Janeiro: Nova fronteira, 2002.

CEBDS (Conselho Empresarial Brasileiro para o Desenvolvimento Sustentável). Ecoeficiência. Disponível em: < http://www.cebds. com > . Acesso em: 20 mar. 2004.

MCT (Ministério da Ciência e Tecnologia). Correção dos valores para considerar a combustão incompleta. Disponível em: http://www.mct. gov.br > . Acesso em: 04 fev. 2005.

MDIC (Ministério do Desenvolvimento Indústria e Comércio Exterior). Sistema aliceweb. Disponível em: < http://www.desenvolvimento.gov. br > . Acesso em: 15 fev. 2005.

RIBEIRO, R. A. Economia piauiense. Teresina, 2001, 61 p. Trabalho não publicado.

UNCTAD (United Nations Conference on Trade and Development). Manual for the preparers and users of eco-efficiency indicators. Version 1.1, United Nations, New York and Geneva, 2004.

VALE, A. T. do, et. al. Estimativa do consumo residencial de lenha em uma pequena comunidade rural do município de São João D’ Aliança, GO. In: Ciência Florestal, v. 13, n. 2, p.159-165, 2003. 
VINHA, V. da. As empresas e o desenvolvimento sustentável: da ecoeficiência à responsabilidade social corporativa. In: LUSTOSA, M. C.; MAY, P. H.; VINHA, V. da. (Org.). Economia do meio ambiente. Rio de Janeiro: Elsevier, 2003. p.173-196.

WBCSD (World Business Council for Sustainable Development). Eco-efficiency - creating more value with less impact. October, 2000. Disponível em: < http://www.wbcsd.ch > . Acesso em: 28 mar. 2004. 